SIR,-Professor A. L. Cochrane, in his report on the 20-year follow-up of miners and non-miners examined in the Rhondda Fach in 1950-51 (2 June, p. 532), showed tha the survival of the miners was independent of the radiological category between category 0 and category $A$ but that there was a decrease in the survival rate of men with progressive massive fibrosis of categcry $\mathrm{B}$ or $\mathrm{C}$.

The method he used to classify the chest $x$-rays was essentially similar to that ultimately recommended by the Internationa Labour Office in their Radiological Classification of Coalworkers' Pneumoconiosis (Geneva 1958). This was based upon the extent of simple nodulation and of massive fibrosis, but it did not pay regard to other evidence of functional disability in the lung. The 1968 I.L.O. classification recommended that nodulation should be classified separately from irregular markings. Though the primary purpose of this addition was for use in the asbestoses, it has proved useful in the anthracoses.

If the Rhondda miners in radiological category 0 contained cases with significan clinical pneumoconiosis which did not present as nodulation, then the failure to detect a gradient in survival rates with increased nodulation would not be evidence of the failure of the disease to influence survival. This hypothesis could be put to the proof by examination of the lung sections of the deceased miners where these are still available. Professor Cochrane's own data suggest that some such phenomenon may be occurring. We have calculated standardized mortality ratios for each of his radiological categories for each decade of age using as a standard a mean of the survivals between the 1951 and the 1971 life tables calculated by the Registrar General for England and Wales. ${ }^{2}$ These are shown in the table.

It will be seen that there was a cohort phenomenon; all miners aged $35-44$ years in 1950 had a high mortality ratio irrespective of category of radiology, miners aged 45-54 had a high mortality ratio in category $\mathbf{O}$ and also in categories $B$ and $\mathrm{C}$, and miners aged over 55 in the original survey did not have high mortality.

It has been our experience ${ }^{2} 3$ that some patients labelled radiologically category 0 or 1 during life showed a substantial degree of pneumoconiosis usually accompanied by extensive emphysema at postmortem examination. Similar findings have been reported by Naeye ${ }^{4}$ and by Naeye and Dellinger. ${ }^{5}$ They concluded that "a number of miners with no roentgenographic evidence of pneumoconiosis had
Coalworkers' Pneumoconiosis

emphysema, cor pulmonale and dyspnoea in addition to dust macules and nodules with silica and collagen."

Professor Cochrane in this preliminary account of survival at 20 years does not consider the question of disablement in the Rhondda miners, but he did report on a sample of his cases aged 55-64 in 1958 in an earlier paper, ${ }^{6}$ where he showed that there was no evidence of a gradient of decreasing pulmonary function in categories $0,1,2,3$, or $\mathrm{A}$, but there was an abrupt fall with onset of massive fibrosis of category B or C. We found, when examining serial ventilatory capacity tests in disabled miners with pneumoconiosis, a similar lack of association with nodulation up to category B, but that impairment of ventilation was usualiy associated with emphysema found at postmortem examination and that the impairment was gradually worse as the emphysema increased. Such findings would seem to be more in keeping with the known nature of coalworkers' pneumoconiosis rather than the abrupt deterioration at an artificial radiological stage of the disease.

An alternative interpretation of the Rhondda findings could be that the impairment of ventilation found in all the category 0 to $A$ groups is, in fact, due to coalworkers' pneumoconiosis, but this is not necessarily related to a purely nodular radiological classification of pneumoconiosis which takes no account of parenchymal involvement including emphysema. For these reasons we believe that Professor Cochrane's findings should be treated with reserve.-We are, etc.,

H. CAMPBell

J. P. LYONS J. GOUGH

Department of Medical Statistics,

Welsh National School of Medicine,

R. RYDER

1 Registrar General's Statistical Review of England and Wales, 1951 Pt II (Civil) and 1971, Par 1973.

2 Ryder, R., Lyons, J. P., Campbell, H., and Gough, Ryder, R., Lyons, J. P., Campbell, H., and Cout J., British Medical Fourna, 1970, 3, 481.
Lyons, J., P., Ryder, R., Campbell, H.; Gough, J., Naeye, R. L. Annals of the New Yor emy of Science, $1972,200,381$. Naeye, R. L., and Dellinger, W. S., Fournal of the American Medical Association, 1972, 220, 223.

Cochrane, A. L., Higgins, I. T. T., and Thomas, Medicine, 1961, 15, 1 .

Misuse of Drugs Regulations 1973

SIR,-Tightening up the regulations governing the prescribing of dangerous drugs can do nothing but good, but I have yet to meet a general practitioner who can tell me pre-

Rhondda Fach Survey, 1950-1; Ratio of Actual to Expected Deaths (Excluding Deaths Due to Industrial Trauma)

\begin{tabular}{|c|c|c|c|c|c|c|c|}
\hline \multirow{2}{*}{$\begin{array}{c}\text { Age at Survey } \\
\text { (years) }\end{array}$} & \multicolumn{6}{|c|}{ Category of Pneumoconiosis } & \multirow{2}{*}{$\begin{array}{l}\text { Non } \\
\text { Miners }\end{array}$} \\
\hline & 0 & 1 & 2 & 3 & $\mathbf{A}$ & $\mathbf{B}+\mathbf{C}$ & \\
\hline $\begin{array}{l}25-34 \\
35-44 \\
45-54 \\
55-64 \\
65-74 \\
75 \text { and over }\end{array}$ & $\begin{array}{l}0.77 \\
1.17 \\
1.27 \\
1.10 \\
0.98 \\
1.03\end{array}$ & $\begin{array}{l}(0.67) \\
1.56 \\
1.18 \\
1.06 \\
1.00 \\
1.17\end{array}$ & $\begin{array}{l}(1 \cdot 0) \\
1 \cdot 46 \\
1 \cdot 14 \\
1 \cdot 10 \\
1 \cdot 04 \\
1 \cdot 10\end{array}$ & $\begin{array}{l}(1 \cdot 6) \\
1.37 \\
0 \cdot 85 \\
0.97 \\
1 \cdot 05 \\
(1 \cdot 33)\end{array}$ & $\begin{array}{r}(0.67) \\
1.57 \\
1.18 \\
1.20 \\
0.94 \\
1.00\end{array}$ & $\begin{array}{l}(2.50) \\
3.33 \\
1.83 \\
1.24 \\
1.06 \\
1.15\end{array}$ & $\begin{array}{l}1.11 \\
1.10 \\
0.91 \\
1.03 \\
0.96 \\
1.00\end{array}$ \\
\hline All Ages & $1 \cdot 10$ & $1 \cdot 11$ & $1 \cdot 13$ & 1.07 & 1.13 & 1.41 & 0.99 \\
\hline
\end{tabular}

Numbers in parentheses refer to groups with fewer than 10 deaths. cisely which drugs are included in the new sohedule. There is a great deal of confusion for as far as I know the Department of Health has not yet issued a list of branded drugs whioh are involved. It seems to me that this would be an excellent moment for the Department to remind us all which drugs are in which categories. When they do so they should bear in mind the fact that few practitioners use chemical or generic names when prescribing.-I am, etc.,

Inkpen, Berks

V. E. Coleman

\section{The Community Hospital}

SIR,-I was intrigued to read the recent article by Dr. J. Weston Smith and others (26 May, p. 471) emphasizing the role which general practitioners may play in a community hospital. It is surprising that there continues to be any doubt or need for discussion on this matter.

I am a consultant surgeon in a town similar in size to Tamworth in which 16 G.P.s provide a comprehensive medical service, which includes the total management of two general hospitals comprising a total of 250 beds. There are no resident junior hospital staff. The only consultants available are myself, a radiologist, and a psychiatrist. Patients are referred to consultants with specific problems requiring specialized management. The maiority of the patients are quite adequately cared for by their family doctors. Many of the doctors have higher qualifications or specialized experience and are always available to help or advise one another.

This system of patient management appears to be a satisfactory and satisfying alternative to the more common hierarchical structure found in city hospitals. In fact, it is my observation that decisionmaking is more rapid, bed turnover more rapid, and patient treatment and satisfaction at least as good as one finds in the more traditional hospital staff structure. Indeed, I feel this is a model which should be more closely observed as a possible alternative to the usual British system. From this distance it seems extraordinary that G.P.s who may have some years of hospital experience and higher qualifications may not necessarily have access to their district hospitals.

If we were to adopt a hierarchical hospital staff structure in my town, we have estimated that this would require at least 12 additional doctors to fill the junior hospital staff posts. In this age of an increasing shortage of medical personnel it might be wise to re-examine the necessity for resident hospital staff, except for specialized units.-I am, etc.,

Bunbury

I. V. LishMAN Western Australia

\section{Hospital Activity Analysis Statistics}

SIR,-I recently received from the SouthWest Metropolitan Regional Hospital Board my latest batch of H.A.A. statistics referring to the first quarter of 1973 . They seem grossly inaocurate; the number of patients recorded as leaving in this quarter 